\title{
Does Trade Openness Affect the Speed of Output Convergence? Some Empirical Evidence*
}

\author{
David E. A. Giles \& Chad N. Stroomer \\ Department of Economics \\ University of Victoria
}

June 2003

\begin{abstract}
In this paper we develop flexible techniques for measuring the speed of output convergence between countries when such convergence may be of an unknown non-linear form. We then calculate these convergence speeds for various countries, in terms of half-lives, from two timeseries data-sets. These calculations are based on both nonparametric kernel regression and 'fuzzy' regression, and the results are compared with more restrictive estimates based on the assumption of linear convergence. The calculated half-lives are regressed, again in various flexible ways, on cross-section data for the degree of openness to trade. We find evidence that favours the hypothesis that increased trade openness is associated with a faster rate of convergence in output between countries.
\end{abstract}

Keywords: $\quad$ Trade openness; output convergence speed; fuzzy clustering; robust regression; Lyapunov coefficient

JEL Classifications: $\mathrm{C} 14 ; \mathrm{C} 21 ; \mathrm{C} 22 ; \mathrm{F} 15 ; \mathrm{F} 43 ; \mathrm{O} 4$

\section{Author Contact:}

Professor David E.A. Giles, Department of Economics, University of Victoria, P.O. Box 1700, STN CSC, Victoria, B.C., Canada V8W 2Y2; email: dgiles@uvic.ca; Voice: (250) 721-8540; FAX: (250) 721-6214 


\section{Introduction}

There is a long history of research, both theoretical and empirical, that provides at least a consensus affirmative answer to the question: 'Does openness to trade result in the growth of income (say, GDP)?' When the question is refined to become: 'Is openness to trade associated with convergence in income (output) across countries?', the answer is less clear. However, there is recent empirical evidence that supports a further positive answer, and so in this paper we refine the question even further, and ask: 'Does openness to trade affect the speed of convergence in output across countries?' This question does not appear to have been the subject of systematic empirical analysis before.

In this paper we present empirical evidence that offers reasonable support for the hypothesis that there is a positive relationship between the speed of output convergence and trade openness. The latter is defined as a country's total trade (exports plus imports) as a fraction of GDP; and the sped of output convergence is measured in terms of the half-life for closing the 'gap' between a country's real per capita GDP and that of the 'leading' country in the group under consideration. We base our analysis on two sets of data, one relating to 22 industrialized OECD countries, and another involving 88 countries at various levels of development. In each case the leading country is the U.S.A..

The convergence half-lives are constructed from time-series data, allowing for both linear and nonlinear convergence. Following a recent suggestion in the purchasing power parity literature, they are based on estimates of the Lyapunov exponents of the output data. Linear and nonlinear cross-section regressions are then estimated to test if there is a significant negative relationship between convergence half-lives and trade openness. At both stages of the analysis we make extensive use of some new results relating to regression modeling based on fuzzy clustering, and we use quantile regression and other robust procedures to deal with outliers in the data.

In the next section we provide a brief discussion of the literature associated with the questions that were posed in the opening paragraph above. Section 3 provides the details of the estimation of the output convergence speeds, and links our analysis to the purchasing power parity literature. Fuzzy clustering and fuzzy regression methods are introduced in section 4; and the data that are used in our empirical analysis are described in section 5. Our main results relating to both output convergence half-lives, and the negative link between these and trade openness, appear in section 6; and section 7 concludes the paper with a summary and some comments on future research. 


\section{Output Convergence and Trade}

Empirical testing of the income convergence hypothesis has been based on both cross-section and time-series data, with mixed results. Essentially, the cross-section results have supported convergence, while the earlier time-series results did not. For further details, see Baumol (1986), Dowrick and Nguyen (1989), Barro (1991), Mankiw et al. (1992), Bernard (1992), Quah (1993), Barro and Sala-i-Martin (1991, 1992, 1995), Bernard and Durlauf (1995, 1996), Cellini and Scorcu (2000), inter alia, and the excellent survey by Durlauf and Quah (1999). However, the more recent time-series evidence has been more favourable towards the convergence hypothesis. Greasley and Oxley (1997) find more convergence than do Bernard and Durlauf (1995) by taking account of structural breaks in the data; and using a Kalman filter approach St. Aubyn (1999) finds convergence, after World War 2, between the U.S.A. and every G-7 country except Canada. Nahar and Inder (2002) criticize the definition of convergence that is used by Bernard and Durlauf, and the alternative approach that they propose yields evidence of convergence between 16 out of 21 OECD countries, relative to the U.S.A.. The robustness of their results to changes in the sample period and set of countries is demonstrated by Giles and Hui (2003).

This evidence in favour of the output convergence hypothesis prompts us to return to the second question posed above: 'Is openness to trade associated with convergence in income (output) across countries?' Standard international trade theory provides only a few strong results that lead to a clear answer. It is clear that the flows of goods and services between countries will lead to the convergence of factor prices - at least under the rather strong assumptions of the factor price equalization theorem (Samuelson, 1948, 1949). However, as we discuss more fully below, convergence in factor prices need not imply convergence in output, and even if trade openness and output convergence co-exist, this does not necessarily imply that there is a causal relationship between the two. Neither does it mean that other variables are unimportant to the process of output convergence.

In the context of the economic growth literature, very little is said with regard to the role of international trade in the convergence process. In the traditional Solow-Swan model, convergence emerges in a closed-economy environment. In those endogenous growth models that allow for trade, the focus is on convergence to a steady-state rather than on convergence in the levels of output in different economies. These points have been made already by Slaughter $(1997,2001)$, Ben-David (1996), Ben-David and Loewy (1998), Ben-David and Kimhi (2000) and others. 
Several of these authors, and others, have enhanced our understanding of this issue through various empirical studies. The results have been mixed, depending upon the definition of convergence that is adopted, the choice of statistical technique, the type of data, the time-period in question, and the level of development of the countries under consideration. The conclusions that emerge also depend at least partly on the distinction between studies that investigate trade liberalization and output convergence, and those that deal with the degree of openness to trade and convergence.

The few theoretical models and results that are available relate primarily to trade liberalization, which is not of explicit concern to us here. For example, Ben-David and Loewy $(1998,2000)$ develop models that predict that while trade liberalization will increase the steady-state output growths of all countries, those countries that participate directly in this liberalization most will benefit the most in terms of their relative income levels. Our own concern is with relationships between per capita output convergence and existing levels, or amounts, of trade (as reflected in the degree of openness of the economies in question). In this case, there are very few formal theoretical models to help us, and even fewer sharp results. Slaughter (1997) critiques three ways in which, it has been argued by various authors, trade may be associated with output convergence.

First, he points that the factor price equalization theorem relates to steady-state free-trade equilibria, whereas the notion of 'convergence' relates to movements towards a steady-state situation. Moreover, as he observes, even when factor prices are converging, if factor endowments are diverging sufficiently then per capita incomes can also diverge. Second, Slaughter notes that while trade can facilitate technology transfer between economies, and thus change the countries' factor prices, for this to result in changes in per capita output, we must avoid situations in which factor endowments are diverging sufficiently to offset the technology transfer effects. Finally, he observes that while it is possible for trade in capital goods to result in convergence in per capita outputs (by changing the countries' relative factor endowments), such convergence will not occur if factor prices are diverging too quickly. There seems to be no compelling theoretical reason that per capita income convergence and international trade must co-exist

As we have noted already, the associated empirical literature provides us with somewhat mixed evidence. Several of these recent empirical studies (e.g., Ben-David 1993, 1994, Ben-David and 
Bohara, 1997), Ben-David and Kimhi (2000), and Slaughter (2001) focus on countries that have been involved in trade liberalization programs. The consensus of the results from all but the last of these studies is that there is a positive association between trade liberalization and per capita income convergence. In contrast, Slaughter (2001) finds that various post-1945 trade liberalizations appear to have led to income divergence, rather than convergence. On the other hand, Dollar (1992), Edwards (1993), Harrison (1996), Sachs and Warner (1995), Henrekson et al. (1997), Ben-David (1996), Giles (2001) and Stroomer and Giles (2003) all focus on the level of trade (or trade openness), rather than situations associated with trade liberalization programs, and their general conclusion is that there is a positive relationship between trade and per capita output convergence. On the negative side, O'Rourke (1996) concludes that migration was more important than trade for international convergence in the late nineteenth century; and Bernard and Jones (1996) conclude that freer trade results in income divergence across countries. In summary, while the jury is still out as to the role of trade openness in the output convergence process, much of the recent empirical evidence points to a positive association of some sort, and this suggests that more detailed investigations of these linkages would be interesting and useful.

\section{Measuring the Speed of Convergence}

Given that there is at least some evidence in support of income convergence between countries, and that trade openness may play a role in this, it is natural to turn to the final question posed in our opening remarks in section 1. 'Does trade openness affect the speed of output convergence?'

In the international trade literature, a number of authors (e.g., see Frankel, 1986, Diebold et al., 1991, Lothian and Taylor, 1996, and Rogoff, 1996) have measured the speed of convergence to purchasing power parity (PPP) by estimating the half-lives of deviations from PPP. We use this approach here to measure the speed of convergence in output by calculating half-lives of deviations from the output of the 'leading' country. In the PPP literature, the traditional way of obtaining such an estimate is to fit a simple $\operatorname{AR}(1)$ regression for the real exchange rate $(q)$ :

$$
q_{t}=\rho q_{t-1}+\varepsilon_{t}
$$

and then obtain the convergence half-life as

$$
\tau=\ln (0.5) / \ln (|r|)
$$


where ' $r$ ' is the Ordinary Least Squares (OLS) estimator of the slope parameter in (1), and the denominator in (2) measures the (absolute) speed of adjustment in the AR(1) process. ${ }^{1}$

Given the linearity of (1), the half-life in (2) is uniquely defined, independently of the initial value, $q_{0}$, and of the values of the deviations from PPP. While this assumed linearity is convenient, it is highly restrictive, and can lead to a bias in half-life estimates (Taylor, 2001). A number of recent studies (e.g., Michael et al., 1997, Obstfeld and Taylor, 1997, O'Connell, 1998, Obstfeld and Rogoff, 2000, Taylor et al., 2001 and Shintani, 2002) have argued that one should use a smooth nonlinear AR(1) model:

$$
q_{t}=f\left(q_{t-1}\right)+\varepsilon_{t}
$$

where $f\left(q_{t-1}\right)$ is a nonlinear conditional mean function. ${ }^{2}$ In this case, defining a half-life measure is complicated by the fact that the nonlinear response function depends upon the initial value, $q_{0}$, and on the magnitudes and the signs of the shocks.

Recently, Shintani (2002) has explored the use of the largest Lyapunov exponent of the timeseries for $q_{t}$ as the basis for half-life measurement. ${ }^{3}$ For the model (3), the Lyapunov exponent is defined as:

$$
\lambda=\lim _{T \rightarrow \infty} T^{-1} \sum_{t=1}^{T} \ln \left|D f\left(q_{t-1}\right)\right|,
$$

where $D f\left(q_{t-1}\right)$ is the first derivative of the conditional mean function for (3). Shintani (2002) exploits the fact that as the Lyapunov exponent in a stable system with a steady state can be interpreted as an average speed of adjustment, a half-life measure analogous to that in (2) can be constructed as ${ }^{4}$

$$
\tau^{*}=\ln (05) / \lambda
$$

Furthermore, Shintani then proposes that $D f\left(q_{t-1}\right)$ can be estimated by fitting model (3) using nonparametric kernel regression, and obtaining the derivatives, $d f\left(q_{t-1}\right)$, of the fitted function. ${ }^{5}$ Inserting these derivative estimates into (4) provides an estimator of (4), namely

$$
l=T^{-1} \sum_{t=1}^{T} \ln \left|d f\left(q_{t-1}\right)\right|
$$


for use in (5). Shintani notes that although the resulting estimator of (5) (say, $t^{*}$ ) is not an exact half-life measure, it can be interpreted as the average of the half-lives of the locally linearized nonlinear processes.

Obtaining meaningful estimates of $D f\left(q_{t-1}\right)$ by nonparametric kernel regression is problematic if the sample size is limited. In such cases, the highly flexible fuzzy regression estimator discussed by Giles and Draeseke (2003) is an attractive alternative, as is amply demonstrated by those authors. As we explain in the next section, fuzzy regression is able to capture arbitrary nonlinearities in the model extremely well, and it provides consistent parameter estimates. It has the added advantage of being totally free of the so-called 'curse of dimensionality' associated with kernel regression, which is of crucial importance if the autoregressive process in (3) were to be extended to an order higher than unity, resulting in additional variables in the conditional mean function.

In the present study we are concerned estimating the relationship between the speed of output convergence and the level of trade openness. To facilitate this we need quantitative measures of the speed of convergence of output to that of a 'leading' country. To the best of our knowledge, the only similar such measures that have been obtained previously by using time-series data are those of St. Aubyn (1999) for the G-7 countries, relative to the U.S.A.. ${ }^{6}$ His measures are in terms of each country's annual percentage rate of convergence to its long-run steady-state. When these are converted to half-lives, his five statistically significant estimates correspond to values that range between 5.1 and 13 years. ${ }^{7}$ Clearly, St. Aubyn's results provide insufficient data for an analysis of the type that we have in mind. Moreover, a point that has not been addressed in the literature to date is that if output convergence takes place, then it may follow a nonlinear process. This suggests that Shintani's half-life measure, based on the Lyapunov exponent, may be a useful way of quantifying convergence rates in this context.

In the analysis that follows we use the derivatives of estimated fuzzy regression models to construct half-life estimates, $t^{*}$, in view of the limited sample sizes that we are dealing with, though we also use nonparametric kernel regression with one of our data-sets for illustrative purposes. Using the fuzzy regression approach to estimate the conditional derivative functions has the added advantage of enabling us to deal with outliers in the data in a very simple but effective manner. 


\section{Fuzzy Regression Analysis}

The following discussion is taken directly from Giles and Draeseke (2003), Stroomer and Giles (2003), and Giles and Mosk (2003). Fuzzy sets were first introduced by (Zadeh, 1965, 1987). The fuzzy c-means (FCM) algorithm (Ruspini, 1970, Bezdek, 1973, 1981; Dunn, 1974, 1977;) partitions the ' $n$ ' data-points into ' $c$ ' fuzzy clusters (where $c<n$ ), and simultaneously identifies the centers of these clusters. Let $\boldsymbol{x}_{k}$ be the $k^{\text {th }}$ (possibly vector) data-point $(k=1,2, \ldots ., n)$; let $\mathbf{v}_{\mathrm{i}}$ be the center of the $i^{\text {th }}$ (fuzzy) cluster $(i=1,2, \ldots ., c)$; let $d_{i k}=\left\|\boldsymbol{x}_{k}-\boldsymbol{v}_{i}\right\|$ be the distance between $\boldsymbol{x}_{k}$ and $v_{i}$; and let $u_{i k}$ be the 'degree of membership' of data-point ' $k$ ' in cluster ' $i$ ', where :

$$
\sum_{i=1}^{c}\left(u_{i k}\right)=1
$$

We partition the data into the ' $c$ ' clusters, locate the cluster centers, and determine the associated 'degrees of membership', so as to minimize the functional

$$
J(U, v)=\sum_{i=1}^{c} \sum_{k=1}^{n}\left(u_{i k}\right)^{m}\left(d_{i k}\right)^{2}
$$

Values are assigned in advance for ' $m$ ' ( $>1)$, and ' $c$ '. The latter choice is constrained in part by the sample size, and after some experimentation we have used $c=3$. We have set $m=2$, which is a common choice. The FCM algorithm involves the following steps:

1. Select the initial locations of the cluster centers.

2. Generate a (new) partition of the data by assigning each data-point to its closest cluster center, based on the membership values.

3. Calculate new cluster centers from the revised partition of the data.

4. If the cluster partition is stable then stop. Otherwise go to step 2 above.

The Lagrange multiplier technique generates the following expression for the membership values to be used at step 2 above:

$$
u_{i k}=1 /\left\{\sum_{j=1}^{n}\left[\left(d_{i k}\right)^{2} /\left(d_{j k}\right)^{2}\right]^{1 /(m-1)}\right\} .
$$


The cluster centers are updated at step 3 above via the expression

$$
v_{i}=\left[\sum_{k=1}^{n}\left(u_{i k}\right)^{m_{x}}\right] /\left[\sum_{k=1}^{n}\left(u_{i k}\right)^{m}\right] ; \quad i=1,2, \ldots ., c .
$$

The fixed-point nature of this problem ensures the existence of a solution in a finite number of steps. When the centers of the fuzzy clusters have been determined, each of the $n$ data-points can be allocated to the cluster whose center it is closest to.

To illustrate fuzzy regression, consider the case where there is a single regressor (other than, perhaps, a constant intercept). ${ }^{8}$ The fuzzy relationship to be estimated is:

$$
y=f(x)+\varepsilon \quad,
$$

where the form of the functional relationship is unspecified (but will typically involve unknown parameters), and $\varepsilon$ is a random disturbance term. No distributional assumptions need to be made about the latter. If the disturbance has a zero mean, the fuzzy function represents the conditional mean of the dependent variable, $y$. To this extent, the framework is the same as that which is adopted in non-parametric kernel regression.

The identification and estimation of the fuzzy model proceeds according to the following additional steps, once the fuzzy clusters have been established using the FCM algorithm:

5. Using the data for each fuzzy cluster separately, fit the models:

$$
y_{i j}=f_{i}\left(x_{i j}\right)+\varepsilon_{i j} \quad ; j=1, \ldots, n_{i} ; i=1, \ldots ., c
$$

In particular, if the chosen estimation procedure is parametric least squares, then

$$
y_{i j}=\beta_{i 0}+\beta_{i 1} x_{i j}+\varepsilon_{i j} \quad ; j=1, \ldots, n_{i} ; i=1, \ldots ., c
$$

6. Recalling that

$$
\sum_{i=1}^{c}\left(u_{i k}\right)=1
$$

model and predict the conditional mean of $y$ using: 


$$
\hat{y}_{k}=\left[\sum_{i=1}^{c}\left(b_{i 0}+b_{i 1} x_{k}\right) u_{i k}\right] ; k=1, \ldots ., n
$$

where $u_{i k}$ is the degree of membership of the $k^{\text {th }}$ value of $x$ in the $i^{\text {th }}$ fuzzy cluster, and $b_{i m}$ is the least squares estimator of $\beta_{i m}(m=0,1)$ obtained using the $i^{\text {th }}$ fuzzy partition of the sample.

7. Construct the derivative of the conditional mean with respect to the input variable:

$$
\left(\partial \hat{y}_{k} / \partial x_{k}\right)=\sum_{i=1}^{c}\left(b_{i 1} u_{i k}\right) \quad ; k=1, \ldots ., n
$$

The fuzzy predictor of the conditional mean of $y$ is a weighted average of the linear predictors based on the fuzzy partitioning of the explanatory data, with the weights (membership values) varying continuously through the sample. This latter feature enables non-linearities to be modeled effectively. In addition, it can be seen that the separate modeling over each fuzzy cluster involves the use of fuzzy logic of the form "IF the input data are likely to lie in this region, THEN this is likely to be the predictor of the output variable", etc.. The derivative of the fuzzy conditional mean has the same potential for non-linearity. Under some very mild conditions, the fuzzy regression estimator is weakly consistent, and its rate of convergence is the same as that for the least squares estimator, namely $T^{l / 2}$. In contrast, nonparametric kernel regression suffers from the well-known 'curse of dimensionality' and it converges in probability increasingly slowly as the number of regressors grows. ${ }^{9}$

\section{Data Issues}

In this study we use two different sets of data to examine the relationship between the half-life of convergence in output to a 'leader', and trade openness. The first of these is that used by Nahar and Inder (2002), and it provides real per capita GDP for 22 OECD countries over the period 1950 to 1998. These data are essentially from the Penn World Table (Summers and Heston, 1995), with some extensions (and adjustments in the case of Germany) that are discussed by Nahar and Inder (2002, p. 2015). We have taken the trade openness data (OPEN) for each of these countries from the Penn World Table, where openness is defined as the ratio of total nominal trade (i.e., exports plus imports) to mominal GDP. The real GDP time-series data are used to construct output convergence half-lives for each country with respect to the 'leading' country, the U.S.A. This provides a cross-section of 21 half-lives, and we take the trade openness 
of each country in 1950 to get the corresponding cross-section for openness. We also repeated the analysis by taking the average of trade openness over the period 1950-1960 for each country. The results presented in the next section are totally robust to this choice of definition.

The second set of data is that used by Stroomer and Giles (2003). It comprises per capita GDP data in real (1985) international prices, adjusted for terms of trade (RGDPTT), and trade openness data (OPEN) for 88 countries, over the period 1965 to 1990. The names of the countries in the sample are given in Tables 1 to 3 of Stroomer and Giles (2003). In keeping with other authors we have not included those oil-producing countries with extremely high per capita incomes in our sample. The countries in this sample have trade openness values that span a very wide range, and Stroomer and Giles divided the countries into three groups, according to their openness, by using the fuzzy c-means clustering algorithm. This resulted in a low-openness cluster of 50 countries; a medium-openness cluster of 21 countries; and a high-openness cluster of 17 countries. The results presented in the next section are based on output convergence half-lives that are estimated from the GDP data for each of the 87 countries (relative to the overall 'leader', the U.S.A.). We also conducted the same analysis, separately, for each of the openness clusters constructed by Stroomer and Giles, considering convergence to each cluster leader. ${ }^{10}$ However, we were unable to obtain sensible results in this case, apparently due to the lack of dispersion in the relatively small samples. In addition, we repeated the analysis by taking the average of trade openness over the period 1965-1969 for each country, and once again the results given in the next section are robust to this choice of definition.

\section{Empirical Results}

We have constructed output convergence half-lives using Shintani's (2002) approach, as outlined in section 3. Estimates of the derivatives needed to calculate the half-life values have been obtained by five different methods. These are: (i) OLS estimation of the linear AR(1) model (1), and the application of equation (2) above; (ii) as for (i), but with robust 'five quantile' (5Q) estimation replacing OLS to allow for outliers in the data; (iii) fuzzy regression estimation of the nonlinear AR(1) model (3), with OLS applied at step 5 of the discussion in section 4 above, and the half-lives calculated from the Lyapunov exponent using equations (4), (5) and (6); (iv) as for (iii), but with '5Q' estimation in place of OLS; and (v) as for (iii), but with nonparametric kernel regression used instead of fuzzy regression. 
Table 1

Half-Life Estimates*

Method for Constructing Half-Lives

OLS 5Q Fuzzy Regression Nonparametric

OLS 5Q

(a) Nahar \& Inder Data

$\begin{array}{lccccc}\mathbf{N}_{+} & 20 & 20 & 18 & 18 & 21 \\ \text { Mean } & 12.7 & 11.7 & 5.7 & 8.3 & 1.1 \\ \text { Median } & 10.6 & 9.3 & 2.8 & 3.5 & 1.0\end{array}$

(b) Stroomer \& Giles Data

$\begin{array}{llllll}\mathbf{N}_{+} & 37 & 27 & 66 & 53 & 87 \\ \text { Mean } & 76.4 & 9.1 & 6.7 & 16.6 & 1.4 \\ \text { Median } & 4.1 & 3.2 & 4.7 & 5.2 & 1.5\end{array}$

* '5Q' denotes robust regression using the 'five quantile' method in the SHAZAM (2001) package.

$\mathrm{N}_{+}$is the number of positive estimated half-lives.

Our calculations of the output convergence half-lives, for both sets of data, are summarized in Table 1 . This summary is based on only those half-life estimates that are positive. While these values are not of primary concern to us in their own right, they represent the data for the dependent variable in the models that we use to examine the relationship between convergence and trade openness. Accordingly, it is important to consider their characteristics and also to compare them with other evidence on output convergence rates. As was noted in section 3, St. Aubyn (1999) provides limited such evidence based on time-series data for G-7 countries, suggesting half-lives of between 5.1 and 13 years. The median values reported in Table 1 are fully consistent with this, except in the case where nonparametric kernel regression (case (v) above) is used. ${ }^{11}$ In the latter case, half-lives of the order of one year arise for every country, regardless of the data-set that is used. This is a questionable result that may be due in part to the 
relatively small sample sizes (21 and 87 observations) that are being used. ${ }^{12}$ Accordingly, we do not use the nonparametric estimates any further in the case of the Nahar and Inder data-set.

Accordingly, we have fitted regression models, either of the simple linear parametric form:

$$
h_{i}=\alpha+\beta o_{i}+\varepsilon_{i} \quad ; i=1, \ldots ., N_{+} \quad ;
$$

or of the more general nonlinear form:

$$
h_{i}=f\left(o_{i}\right)+\varepsilon_{i} \quad ; i=1, \ldots, N_{+} \quad ;
$$

where $h_{i}$ is the half-life for country $i$, and $o_{i}$ is its openness to trade.

Evidence from cross-section studies by Barro and Sala-i-Martin $(1991,1992)$ and Mankiw et al. (1992) and Sali-Martin (1996) suggests convergence speeds of about 2\% p.a. (i.e., a half-life of $h$ $=34.3$ years), but the credibility of these results based on cross-section data has been questioned by Bernard and Durlauf (1995) and others. For example, Evans (1997a) notes that OLS is unlikely to be consistent and instead develops a particular 2SLS estimator. His results for a crosssection of 85 countries imply a convergence rate of $8 \%$ to $9 \%$ p.a. ( $h=7.3$ to 8.3 years). Using panel data for the OECD countries (1960 -1985), Islam (1995) estimated the convergence speed to be $9.13 \%$ p.a. ( $h=7.2$ years). Evans (1997b) also uses panel data - both international and U.S. state-level - and he finds convergence rates of $6 \%$ p.a. $(h=11.2$ years $)$ and $16 \%$ p.a. $(h=4)$ respectively. Finally, Higgins et al. (2003) use a sample for over 3,000 U.S. counties, and report convergence rates of $6 \%$ to $8 \%$ p.a. ( $h=8.3$ to 11.2 years) from 2 SLS regressions, and $2 \%$ p.a. ( $h$ $=34.3$ years) when Evans' OLS estimator is used. This additional evidence also points strongly to the credibility of most of our own half-life estimates, and suggests that these data can be used with some confidence in our subsequent regression analysis.

If increased trade openness is conducive to faster income convergence, we would expect a negative relationship between $h_{i}$ and $o_{i}$. All five methods of constructing the half-lives discussed above have been considered. The regressions themselves have been estimated in various ways. In the case of model (7) we have used OLS (with White's, 1980, correction to the standard errors to guard against possible heteroskedasticity), and four robust estimators, all of which are linear functions of the regression quantiles (Koenker and Bassett, 1978), to guard against data outliers: the five quantile (5Q) estimator noted above; Tukey's (1977) 'trimean' estimator; the Gastwirth (1966) estimator, and the Least Absolute Errors (LAE) estimator. All of these estimators were 
implemented with the SHAZAM (2001) econometrics package. In the case of model (8) we have used nonparametric kernel regression and our own fuzzy regression estimator. The latter was applied in two different ways - with OLS estimation used with models of the form (7) over each of the three clusters; and with the $5 \mathrm{Q}$ estimator used with these three cluster models. ${ }^{13}$

The associated results are summarized in Tables 2 and 3 for our two data-sets, with $a$ and $b$ denoting the estimates of the intercept and slope parameters respectively when the simple parametric model, (7), is used. We are interested primarily in the sign and the significance of the derivative of $h_{i}$ with respect to $o_{i}$. In the case of model (8), these derivatives vary, observation by observation. Accordingly, we report just the (within-sample) median and mean slopes, when estimating this nonlinear model. ${ }^{14}$ Finally, for the fuzzy regressions we also report the results of testing the hypothesis that the slopes of the (linear) within-cluster regressions are equal. With three clusters, the associated Wald test statistic is asymptotically Chi Square with two degrees of freedom, under the null. The associated p-values are given in Tables 2 and 3, and in almost every case we see that the null would be rejected at the $10 \%$ significance level (and often at a much lower level of significance). This provides strong support for estimating separate sub-models over each of the fuzzy clusters, and then combining the results using the membership functions, rather than fitting a single model (by OLS or by robust regression) over the full sample.

The results in table 2 are somewhat 'mixed' perhaps reflecting in part the modest sample size for with the Nahar and Inder data-set. This sample size is typical of many studies of growth convergence in the literature, which suggests that the results associated with those studies should be treated cautiously. The first striking feature of Table 2 is the contrast between the results based on convergence half-lives obtained from OLS and 5Q regression, and those based on half-lives obtained from fuzzy regression analysis. In the former group, no significant negative relationships emerge. In the latter group, negative (and generally significant) relationships are found in most cases, with the only exceptions arising for some situations involving half-lives determined using robust fuzzy regression. One implication of this is that allowing for a flexible, nonlinear, functional form of the type given by equation (3) when estimating convergence half-lives can have an important impact on the conclusions that are reached. This is consistent with the general point that is made by Shintani (2002) in the context of PPP convergence. The most persuasive results emerge when (7) is estimated by the 5Q method, and (8) is estimated by robust or nonrobust fuzzy regression, in each case constructing the convergence half-life data by using (nonrobust) fuzzy analysis. ${ }^{15}$ 
Table 2

Speed of Convergence Regressions*

Method for Constructing Half-Lives

OLS

\begin{tabular}{|c|c|c|c|c|c|c|c|c|}
\hline \multirow[b]{3}{*}{ Estimator } & \multirow{2}{*}{\multicolumn{2}{|c|}{ OLS }} & \multirow{2}{*}{\multicolumn{2}{|c|}{$5 Q$}} & \multicolumn{3}{|c|}{ Fuzzy Regression } & \multirow[b]{3}{*}{ b } \\
\hline & & & & & OLS & & $5 Q$ & \\
\hline & $\mathbf{a}$ & b & $\mathbf{a}$ & b & $\mathbf{a}$ & b & $\mathbf{a}$ & \\
\hline OLS & $\begin{array}{l}6.277 \\
(1.26)\end{array}$ & $\begin{array}{l}0.152 \\
(1.07)\end{array}$ & $\begin{array}{l}6.091 \\
(1.84)\end{array}$ & $\begin{array}{l}0.132 \\
(1.38)\end{array}$ & $\begin{array}{l}7.754 \\
(2.28)\end{array}$ & $\begin{array}{l}-0.052 \\
(-0.62)\end{array}$ & $\begin{array}{l}8.051 \\
(1.81)\end{array}$ & $\begin{array}{l}0.007 \\
(0.05)\end{array}$ \\
\hline $5 Q$ & $\begin{array}{l}10.714 \\
(18.74)\end{array}$ & $\begin{array}{l}0.005 \\
(0.43)\end{array}$ & $\begin{array}{l}7.430 \\
(31.40)\end{array}$ & $\begin{array}{l}0.089 \\
(17.68)\end{array}$ & $\begin{array}{l}5.946 \\
(14.36)\end{array}$ & $\begin{array}{l}-0.063 \\
(-6.71)\end{array}$ & $\begin{array}{l}7.053 \\
(8.88)\end{array}$ & $\begin{array}{l}-0.060 \\
(-3.35)\end{array}$ \\
\hline Gastwirth & $\begin{array}{l}9.366 \\
(8.43)\end{array}$ & $\begin{array}{l}0.036 \\
(1.53)\end{array}$ & $\begin{array}{l}7.734 \\
(4.30)\end{array}$ & $\begin{array}{l}0.084 \\
(2.19)\end{array}$ & $\begin{array}{l}4.710 \\
(4.98)\end{array}$ & $\begin{array}{l}-0.049 \\
(-2.26)\end{array}$ & $\begin{array}{l}5.652 \\
(4.15)\end{array}$ & $\begin{array}{l}-0.045 \\
(-1.45)\end{array}$ \\
\hline Tukey & $\begin{array}{l}10.998 \\
(7.40)\end{array}$ & $\begin{array}{l}-0.012 \\
(-0.38)\end{array}$ & $\begin{array}{l}7.638 \\
(9.61)\end{array}$ & $\begin{array}{l}0.077 \\
(4.53)\end{array}$ & $\begin{array}{l}4.845 \\
(3.34)\end{array}$ & $\begin{array}{l}-0.050 \\
(-1.50)\end{array}$ & $\begin{array}{l}5.821 \\
(5.71)\end{array}$ & $\begin{array}{l}-0.048 \\
(-2.05)\end{array}$ \\
\hline LAE & $\begin{array}{l}9.553 \\
(5.94)\end{array}$ & $\begin{array}{l}0.026 \\
(0.76)\end{array}$ & $\begin{array}{l}8.805 \\
(2.57)\end{array}$ & $\begin{array}{l}0.018 \\
(0.15)\end{array}$ & $\begin{array}{l}4.431 \\
(3.61)\end{array}$ & $\begin{array}{l}-0.049 \\
(-1.74)\end{array}$ & $\begin{array}{l}3.932 \\
(3.06)\end{array}$ & $\begin{array}{l}-0.019 \\
(-0.65)\end{array}$ \\
\hline & $\begin{array}{l}\text { Mean } \\
\text { Slope }\end{array}$ & $\begin{array}{l}\text { Median } \\
\text { Slope }\end{array}$ & $\begin{array}{l}\text { Mean } \\
\text { Slope }\end{array}$ & $\begin{array}{l}\text { Median } \\
\text { Slope }\end{array}$ & $\begin{array}{l}\text { Mean } \\
\text { Slope }\end{array}$ & $\begin{array}{l}\text { Median } \\
\text { Slope }\end{array}$ & $\begin{array}{l}\text { Mean } \\
\text { Slope }\end{array}$ & $\begin{array}{l}\text { Median } \\
\text { Slope }\end{array}$ \\
\hline FuzzyOLS & $\begin{array}{l}1.279 \\
(3.47) \\
{[0.01]}\end{array}$ & $\begin{array}{l}0.149 \\
(2.66)\end{array}$ & $\begin{array}{l}0.834 \\
(2.67) \\
{[0.08]}\end{array}$ & $\begin{array}{l}0.095 \\
(2.57)\end{array}$ & $\begin{array}{l}0.022 \\
(0.07) \\
{[0.00]}\end{array}$ & $\begin{array}{l}-0.059 \\
(-4.38)\end{array}$ & $\begin{array}{l}0.134 \\
(0.35) \\
{[0.07]}\end{array}$ & $\begin{array}{l}0.352 \\
(7.04)\end{array}$ \\
\hline Fuzzy5Q & $\begin{array}{l}1.279 \\
(3.58)\end{array}$ & $\begin{array}{l}0.152 \\
(2.66)\end{array}$ & $\begin{array}{l}0.820 \\
(2.63)\end{array}$ & $\begin{array}{l}0.078 \\
(2.11)\end{array}$ & $\begin{array}{l}-0.019 \\
(-0.06)\end{array}$ & $\begin{array}{l}-0.076 \\
(-5.62)\end{array}$ & $\begin{array}{l}0.115 \\
(0.30)\end{array}$ & $\begin{array}{l}0.180 \\
(3.56)\end{array}$ \\
\hline
\end{tabular}

t-values appear in parentheses. In the case of OLS these are based on White's (1980)

heteroskedasticity-consistent standard errors.

p-values for the Wald test, of the joint hypothesis that the slopes in each of the OLS subregressions for the 3 fuzzy clusters are equal, appear in square brackets. 
Table 3

Speed of Convergence Regressions*

\section{Method for Constructing Half-Lives}

$\begin{array}{llll}\text { OLS } & 5 Q & \text { Fuzzy Regression } & \text { Nonparametric }\end{array}$

\begin{tabular}{|c|c|c|c|c|c|c|c|c|c|c|}
\hline Estimator & $\mathbf{a}$ & b & $\mathbf{a}$ & b & $\mathbf{a}$ & b & $\mathbf{a}$ & b & $\mathbf{a}$ & b \\
\hline OLS & $\begin{array}{l}134.290 \\
(2.49)\end{array}$ & $\begin{array}{l}-1.032 \\
(-1.83)\end{array}$ & $\begin{array}{l}8.230 \\
(2.11)\end{array}$ & $\begin{array}{l}0.013 \\
(0.40)\end{array}$ & $\begin{array}{l}9.091 \\
(5.45)\end{array}$ & $\begin{array}{l}-0.045 \\
(-2.41)\end{array}$ & $\begin{array}{l}17.343 \\
(2.29)\end{array}$ & $\begin{array}{l}-0.019 \\
(-0.19)\end{array}$ & $\begin{array}{l}1.478 \\
(23.8)\end{array}$ & $\begin{array}{l}-0.001 \\
(-0.78)\end{array}$ \\
\hline $5 Q$ & $\begin{array}{l}31.627 \\
(32.04)\end{array}$ & $\begin{array}{l}-0.110 \\
(-8.05)\end{array}$ & $\begin{array}{l}3.910 \\
(4.62)\end{array}$ & $\begin{array}{l}0.025 \\
(2.45)\end{array}$ & $\begin{array}{l}6.134 \\
(13.9)\end{array}$ & $\begin{array}{l}-0.019 \\
(-2.67)\end{array}$ & $\begin{array}{l}8.401 \\
(6.48)\end{array}$ & $\begin{array}{l}0.005 \\
(0.26)\end{array}$ & $\begin{array}{l}1.511 \\
(135.0)\end{array}$ & $\begin{array}{l}-0.001 \\
(-7.78)\end{array}$ \\
\hline Gastwirth & $\begin{array}{l}17.212 \\
(3.19)\end{array}$ & $\begin{array}{l}-0.115 \\
(-1.55)\end{array}$ & $\begin{array}{l}1.344 \\
(1.25)\end{array}$ & $\begin{array}{l}0.040 \\
(3.03)\end{array}$ & $\begin{array}{l}5.529 \\
(8.30)\end{array}$ & $\begin{array}{l}-0.017 \\
(-1.58)\end{array}$ & $\begin{array}{l}6.831 \\
(4.85)\end{array}$ & $\begin{array}{l}-0.025 \\
(-1.03)\end{array}$ & $\begin{array}{l}1.569 \\
(45.9)\end{array}$ & $\begin{array}{l}-0.002 \\
(-3.79)\end{array}$ \\
\hline Tukey & $\begin{array}{l}15.168 \\
(1.84)\end{array}$ & $\begin{array}{l}-0.048 \\
(-0.42)\end{array}$ & $\begin{array}{l}3.030 \\
(2.84)\end{array}$ & $\begin{array}{l}0.030 \\
(2.33)\end{array}$ & $\begin{array}{l}5.826 \\
(8.75)\end{array}$ & $\begin{array}{l}-0.016 \\
(-1.52)\end{array}$ & $\begin{array}{l}6.961 \\
(2.30)\end{array}$ & $\begin{array}{l}0.004 \\
(0.09)\end{array}$ & $\begin{array}{l}1.529 \\
(45.8)\end{array}$ & $\begin{array}{l}-0.002 \\
(-3.10)\end{array}$ \\
\hline LAE & $\begin{array}{l}5.844 \\
(5.45)\end{array}$ & $\begin{array}{l}-0.022 \\
(-1.48)\end{array}$ & $\begin{array}{l}1.234 \\
(2.65)\end{array}$ & $\begin{array}{l}0.042 \\
(7.34)\end{array}$ & $\begin{array}{l}5.296 \\
(5.83)\end{array}$ & $\begin{array}{l}-0.012 \\
(-0.85)\end{array}$ & $\begin{array}{l}6.338 \\
(2.73)\end{array}$ & $\begin{array}{l}-0.025 \\
(-0.72)\end{array}$ & $\begin{array}{l}1.555 \\
(23.9)\end{array}$ & $\begin{array}{l}-0.002 \\
(-1.66)\end{array}$ \\
\hline & $\begin{array}{l}\text { Mean } \\
\text { Slope }\end{array}$ & $\begin{array}{l}\text { Median } \\
\text { Slope }\end{array}$ & $\begin{array}{l}\text { Mean } \\
\text { Slope }\end{array}$ & $\begin{array}{l}\text { Median } \\
\text { Slope }\end{array}$ & $\begin{array}{l}\text { Mean } \\
\text { Slope }\end{array}$ & $\begin{array}{l}\text { Median } \\
\text { Slope }\end{array}$ & $\begin{array}{l}\text { Mean } \\
\text { Slope }\end{array}$ & $\begin{array}{l}\text { Median } \\
\text { Slope }\end{array}$ & $\begin{array}{l}\text { Mean } \\
\text { Slope }\end{array}$ & $\begin{array}{l}\text { Median } \\
\text { Slope }\end{array}$ \\
\hline FuzzyOLS & $\begin{array}{l}-3.325 \\
(-0.25) \\
{[0.60]}\end{array}$ & $\begin{array}{l}-4.486 \\
(-0.27)\end{array}$ & $\begin{array}{l}-0.096 \\
(-0.11) \\
{[0.20]}\end{array}$ & $\begin{array}{l}-0.118 \\
(-1.84)\end{array}$ & $\begin{array}{l}-0.015 \\
(-0.05) \\
{[0.00]}\end{array}$ & $\begin{array}{l}-0.053 \\
(-0.23)\end{array}$ & $\begin{array}{l}0.144 \\
(1.33) \\
{[0.00]}\end{array}$ & $\begin{array}{l}-0.012 \\
(-0.80)\end{array}$ & $\begin{array}{l}-0.005 \\
(-0.27) \\
{[0.00]}\end{array}$ & $\begin{array}{l}-0.006 \\
(-0.58)\end{array}$ \\
\hline Fuzzy5Q & $\begin{array}{l}-1.902 \\
(-0.05)\end{array}$ & $\begin{array}{l}-2.578 \\
(-0.05)\end{array}$ & $\begin{array}{l}-0.029 \\
(-0.05)\end{array}$ & $\begin{array}{l}-0.037 \\
(-0.74)\end{array}$ & $\begin{array}{l}-0.050 \\
(-0.16)\end{array}$ & $\begin{array}{l}-0.108 \\
(-0.46)\end{array}$ & $\begin{array}{l}0.207 \\
(0.16)\end{array}$ & $\begin{array}{l}0.106 \\
(0.12)\end{array}$ & $\begin{array}{l}-0.004 \\
(-0.24)\end{array}$ & $\begin{array}{l}-0.006 \\
(-0.55)\end{array}$ \\
\hline Nonpara & -0.467 & -0.003 & 0.008 & 0.002 & -0.035 & -0.024 & 0.002 & -0.002 & -0.001 & -0.002 \\
\hline
\end{tabular}

* t-values appear in parentheses. In the case of OLS these are based on White's (1980) heteroskedasticity-consistent standard errors.

p-values for the Wald test, of the joint hypothesis that the slopes in each of the OLS subregressions for the 3 fuzzy clusters are equal, appear in square brackets. 
The results in Table 3 relate to the more comprehensive data-set of Stroomer and Giles (2003), and are considerably more uniform. This may be due partly to the larger sample size, which also allowed us to include results based on nonparametric kernel estimation of both (3) and (8) in this table. As was discussed in section 5, Stroomer and Giles undertook their analysis after using fuzzy clustering to divide the countries into three groups, according to their degree of openness. In our modeling here we examined the role of 'openness cluster' dummy variables in model (7), but found them to be totally insignificant. Accordingly, all of our results are based on the full sample of countries, and the sample size is $\mathrm{N}_{+}$, in the terminology of Table 1 . These results for our second data-set are much more supportive of the hypothesis that increased openness in trade promotes a faster rate (shorter half-life) of convergence of output between countries. The only consistent exception to this is when the robust 5Q estimator is used with the linear AR(1) model, (2), to estimate the convergence half-lives. In contrast to the situation in Table 2, the results based on the nonlinear model, (8), suggest an overall negative relationship between half-life and openness, though these mean and median values lack significance. ${ }^{16}$

\section{Conclusions}

In this paper we have undertaken an empirical investigation of one interesting aspect of the relationship between trade openness and economic growth, by considering output convergence and openness, and in particular by considering the speed of output convergence. To measure this speed we have drawn on concepts from the purchasing power parity literature. We have exploited the recent suggestions of Shintani (2002) that one should allow for nonlinear convergence, and measure the half-life of PPP convergence in terms of the Lyapunov exponent of the data This has proven to be an important issue in relation to our output convergence measures. Using this approach we are able to calculate output convergence speeds, country by country, from timeseries data. Such information has not been available on the basis of time-series data previously. Another novel feature of this paper is the application of recent developments in fuzzy clustering and fuzzy regression (e.g., Giles and Draeseke, 2003; Giles and Mosk, 2003), not only to deal with the above-mentioned nonlinearities, but also to allow for very flexible functional forms when modeling the relationship between output convergence speed and trade openness. This flexibility appears to be important in such models, and our results include formal statistical support for this. 
Our main results relate to regressions that 'explain' output convergence half-lives in terms of the degree of trade openness. We are not aware of other results of this type in the literature. Overall, the results from both of the sets of data that we have considered suggest that there is reasonable evidence in support of the hypothesis that increased openness in trade is associated with a short half-life (high speed) of convergence in output across countries. The fact that we are using crosssection data for these regressions, rather than time-series data, precludes any formal testing for the presence and direction(s) of Granger causality between convergence and openness.

There are several directions in which this research can be extended. Clearly, additional sets of data need to be considered before strong conclusions can be drawn. The robustness of our results to the specification of the half-life/openness regressions, especially in terms of controlling for other factors, needs further examination. While the 'curse of dimensionality' associated with nonparametric kernel regression limits its usefulness in the multiple regression context (at least unless the sample size is extremely large), the fuzzy clustering and estimation procedures that we have introduced and used in this paper are readily applied to multiple regression, as Giles and Draeseke (2003) have demonstrated. This promises to be a fruitful basis for a more detailed empirical analysis of the relationship between the speed of output convergence and the degree of trade openness. 


\section{References}

Barro, R. J. (1991), "Economic growth in a cross-section of countries", Quarterly Journal of Economics, CVI, 407-445.

Barro, R. and X. Sala-i-Martin (1991), "Convergence across states and regions", Brookings Papers on Economic Activity, 1, 107-158.

Barro, R. and X. Sala-i-Martin (1992), "Convergence”, Journal of Political Economy, 100, 223251.

Barro, R. J. and X. Sala-i-Martin (1995), Economic Growth, McGraw-Hill, New York.

Baumol, W. J. (1986), "Productivity growth, convergence and welfare: What the long run data show", American Economic Review, 76, 1072-1085.

Ben-David, D. (1993), "Equalizing exchange: Trade liberalization and income convergence", Quarterly Journal of Economics, 108, 653-679.

Ben-David, D. (1994), "Income disparity among countries and the effects of freer trade", in L. L. Pasinetti and R. M. Solow (eds.), Macmillan, London, 45-64.

Ben-David, D. (1996), "Trade and convergence among countries", Journal of International Economics, 40, 279-298.

Ben-David D. and A. Kimhi (2000), "Trade and the rate of income convergence”, Working Paper 7642, NBER, Cambridge, MA.

Ben-David D. and M. Loewy (1998), "Free trade, growth and convergence”, Journal of Economic Growth, 3, 143-170.

Ben-David D. and M. Loewy (2000), “ Knowledge dissemination, capital accumulation, trade and endogenous growth", Oxford Economic Papers, 52, 637-650.

Ben-David, D. and A. Bohara (1997), "Evidence on the contribution of trade reform towards international income equalization", Review of International Economics, 5, 246-255.

Bernard, A. B. (1992), "Empirical implications of the convergence hypothesis", working paper, Department of Economics, MIT, Cambridge, MA.

Bernard, A. B. and S. N. Durlauf (1995), "Convergence in international output", Journal of Applied Econometrics, 10, 97-108.

Bernard, A. B. and C. I. Jones (1996), "Productivity and convergence across U.S. states and industries", Empirical Economics, 21, 113-135.

Bezdek, J. C. (1973), Fuzzy Mathematics in Pattern Classification, Ph.D. Thesis, Applied Mathematics Center, Cornell University, Ithaca, NY.

Bezdek, J. C. (1981), Pattern Recognition With Fuzzy Objective Function Algorithms, Plenum Press, New York. 
Cellini, R. and A. E. Scorcu (2000), "Segmented stochastic convergence across the G-7 countries", Empirical Economics, 25, 463-474.

Diebold, F.-X., S. Husted and M. Rush (1991), "Real exchange rates under the gold standard", Journal of Political Economy, 99, 1252-1271.

Dollar, D. (1992), "Outward-oriented developing economies really do grow more rapidly: Evidence from 95 LDCs, 1976-1985", Economic Development and Cultural Change, 40, 523-544.

Dowrick, S. and D.-T. Nguyen (1989), “OECD comparative economic growth 1950-1985: Catch up and convergence", American Economic Review, 79, 1010-1030.

Dunn, J. C. (1974), "Well separated clusters and optimal fuzzy partitions", Journal of Cybernetics, 4, 95-104.

Dunn, J. C. (1977), "Indices of partition fuzziness and the detection of clusters in large data sets", in M. Gupta and G. Seridis (eds.), Fuzzy Automata and Decision Processes, Elsevier, New York.

Durlauf, S. N. and D. T. Quah (1999), "The new empirics of economic growth", in J. B. Taylor and M. Woodford (eds.), Handbook of Macroeconomics, Vol 1A, Elsevier, Amsterdam, 235-308.

Edwards, S. (1993), “Openness, trade liberalization and growth in developing countries”, Journal of Economic Literature, 31, 1358-1393.

Evans, P. (1997a), "Consistent estimation of growth regressions", unpublished manuscript, Department of Economics, Ohio State University.

Evans, P. (1997b), "How fast do economies converge?", Review of Economics and Statistics, 36, 219-225.

Frankel, J. A. (1986), "International capital mobility and crowding out in the U.S. economy: Imperfect integration of financial markets or of goods markets?”, in R. W. Hafer (ed.), How Open is the U.S. Economy?, Lexington Books, Lexington, 33-67.

Gastwirth, J. L. (1966), “On robust procedures”, Journal of the American Statistical Association, 61, 929-948.

Giles, D. E. A. (2001), "Output convergence and international trade: Time-series and fuzzy clustering evidence for New Zealand and her trading partners, 1950-1992”, Econometrics Working Paper EWP0102, Department of Economics, University of Victoria, and presented at the International Business and Economics Research Conference, Reno NV, October 2001. 
Giles, D. E. A. and R. Draeseke (2003), "Econometric modeling using fuzzy pattern recognition via the fuzzy c-means algorithm", in D. E. A. Giles (ed.), Computer-Aided Econometrics, Marcel Dekker, New York, 407-450.

Giles, D. E. A. and Hui Feng (2003), “Testing for convergence in measures of 'well-being' in industrialized countries", Econometrics Working Paper EWP0303, Department of Economics, University of Victoria.

Giles, D. E. A. and C. A. Mosk (2003), "Ruminant eructation and a long-run environmental Kuznets' curve for enteric methane in New Zealand: Conventional and fuzzy regression analysis", Econometrics Working Paper EWP0306, Department of Economics, University of Victoria.

Harrison, A. (1996), "Openness and growth: A time-series cross country analysis for developing countries", Journal of Development Economics, 48, 419-447.

Henrekson, M., J. Torstensson and R. Torstensson (1997), "Growth effects of European economic integration", European Economic Review, 41, 1537-1557.

Higgins, M., D. Levy, and A. Young (2003), "Growth and convergence across the U.S.: Evidence from county-level data", Working Paper 0306, Department of Economics, Emory University.

Islam, N. (1995), “Growth empirics: A panel data approach”, Quarterly Journal of Economics, $110,1127-1170$.

Koenker, R. and G. W. Bassett (1978), "Regression Quantiles”, Econometrica, 46, 33-50.

Lothian, J. R. and M. P. Taylor (1996), "Real exchange rate behaviour: The recent float from the perspective of the past two centuries", Journal of Political Economy, 204, 488-509.

Mankiw, N. G., D. Romer and D. N. Weil (1992), "A contribution to the empirics of economic growth", Quarterly Journal of Economics, 107, 407-437.

Michael, P., A. R. Nobay and D. A. Peel (1997), "Transaction costs and nonlinear adjustments in real exchange rates: An empirical investigation”, Journal of Political Economy, 105, 862-879.

Nahar, S. and B. Inder (2002), "Testing convergence in economic growth for OECD countries", Applied Economics, 34, 2011-2022.

Obstfeld, M. and K. Rogoff (2000), "The six major puzzles in international macroeconomics: Is there a common cause?", in B. S. Bernanke and K. Rogoff (eds.), NBER Macroeconomics Annual 2000, MIT Press, Cambridge MA. 
Obstfeld, M. and M. P. Taylor (1997), "Nonlinear aspects of goods-market arbitrage and adjustment: Heckscher's commodity points revisited", Journal of the Japanese and International Economies, 11, 441-479.

O'Connell, P. G. J. (1998), "Market frictions and real exchange rates", Journal of International Money and Finance, 17, 71-95.

O’Rourke, K. (1996), “Trade, migration and convergence: An historical perspective”, CEPR Discussion Paper No. 1319.

Quah, D. (1993), “Empirical cross-section dynamics in economic growth”, European Economic Review, 37, 426-434.

Racine, J. and Q. Li (2003), "Nonparametric estimation of regression functions with both categorical and continuous data", forthcoming in Journal of Econometrics.

Rogoff, K. (1996), “The purchasing power parity puzzle”, Journal of Economic Literature, 34, 647-668.

Ruspini, E. (1970), "Numerical methods for fuzzy clustering”, Information Science, 2, 319-350.

Sachs, J. and A. Warner (1995), "Economic reform and the process of global integration", Brookings Papers on Economic Activity, 1, 1-118.

Sal-i-Martin, X. (1996), "Regional cohesion: Evidence and theories of regional growth and convergence", European Economic Review, 40, 1325-1352.

Samuelson, P. A. (1948), "International trade and the equalization of factor prices", Economic Journal, 58, 163-184.

Samuelson, P. A. (1949), "International factor-price equalization once again”, Economic Journal, 59, 181-197.

SHAZAM (2001), SHAZAM Econometrics Package, User's Guide, Version 9, Northwest Econometrics, Vancouver, B.C..

Shintani, M. (2002), "A nonparametric measure of convergence toward purchasing power parity", Working Paper No. 02-W19, Department of Economics, Vanderbilt University.

Slaughter, M. J. (1997), "Per capita income convergence and the role of international trade", American Economic Review, 87, 194-199.

Slaughter, M. J. (2001), “Trade liberalization and per capita income convergence: A differencein-differences analysis, Journal of International Economics, 55, 203-228.

St. Aubyn, M. (1999), “Convergence across industrialized countries (1890-1989): New results using time series methods", Empirical Economics, 24, 23-44.

Stroomer, C. N. and D. E. A. Giles (2003), "Income convergence and trade openness: Fuzzy clustering and time series evidence", Econometrics Working Paper EWP0304, Department of Economics, University of Victoria. 
Summers, R. and A. Heston (1995), The Penn World Table, Version 5.6, National Bureau of Economic Research, Cambridge MA.

Taylor, A. M. (2001), "Potential pitfalls for the purchasing power parity puzzle? Sampling and specification biases in mean-reversion tests of the law of one price", Econometrica, 69, 473-498.

Taylor, M. P., D. A. Peel and L. Sarno (2001), "Nonlinear mean-reversion in real exchange rates: Towards a solution to the purchasing power parity puzzle", International Economic Review, 42, 1015-1042.

Tukey, J. W. (1977), Explanatory Data Analysis, Addison-Wesley, Reading MA.

White, H. (1980), “A heteroscedasticity-consistent covariance estimator and a direct test for heteroscedasticity", Econometrica, 48, 817-838.

Zadeh, L. A. (1965), “Fuzzy sets”, Information and Control, 8, 338-353.

Zadeh, L. A. (1987), Fuzzy Sets and Applications: Selected Papers. Wiley, New York. 


\section{Footnotes}

* We are grateful to Brett Inder for supplying the data used in the study by Nahar and Inder (2002).

1. In practice, an intercept may is usually included in equation (1). Taking the absolute value of the slope estimate allows for the possibility of oscillations.

2. As in (1), we are assuming that the error has a zero mean. In the PPP studies, TAR or STAR models have generally been used to capture nonlinearities in (3).

3. See also Potter (2000), footnote 10.

4. If the system is linear, the expression in (5) collapses to that in (2).

5. Specifically, he uses the local polynomial variant of nonparametric kernel regression, suggested by Fan and Gijbels (1996).

6. The remaining six countries are Canada ( $0.4 \%$ p.a.), France ( $12.7 \%$ p.a.), Germany $(7.7 \%$ p.a.), Italy (5.2\% p.a.), Japan ( $0.5 \%$ p.a.) and the U.K. (6.9\% p.a.). The estimated (constant) convergence speeds are to each country's individual steady-state, based on a sample period of 1890-1989. (The estimates for Canada and for Japan are not statistically significant.) Convergence speeds that emerge from studies based on cross-section and panel data are discussed in section 6 .

7. If the (constant) convergence rate is $r \%$ p.a., the half-life is $h=\{\ln (0.5) / \ln [1-(r / 100)]\}$ years.

8. This is the case that applies in the present study. The following analysis generalizes easily when there are multiple regressors, though some additional concepts from fuzzy set theory (e.g., the counterparts to the usual intersection and union operators) are needed in this case. Giles and Draeseke (2003) provide full details of this, and several modeling applications.

9. Strictly, this is true only if all of the regressors are continuous, rather than discrete, variables - see Racine and $\mathrm{Li}, 2003$, for details.)

10. These leaders are the U.S.A., Switzerland and Luxembourg for the low, medium and high openness clusters respectively.

11. The large mean value for the half-lives from the Stroomer and Giles data-set, based on method (i), is due to one or two extreme values. This underscores the usefulness of using a robust regression estimator.

12. Shintani (2002) uses samples with approximately 100 observations, and his estimated half-lives (for adjustment to PPP) based on nonparametric estimation are generally somewhat smaller than those based on OLS estimation of a linear AR(1) model. 
13. Recall from the discussion above that the half-lives based on nonparametric kernel regression are not used for the Nahar and Inder data-set, and equation (8) is not estimated by kernel regression for these data, given the limited sample size. The NONPAR routine in SHAZAM was used for the kernel regression with the second data-set, and our own code (written in the SHAZAM command language) was used for all of the fuzzy clustering and fuzzy regression analysis. The latter code is available on request to the authors.

14. The 't-values' associated with these mean and median values are asymptotically standard normal.

15. It is interesting to note that this method of producing the half-lives results in the smallest mean and median half-life in Table 1(a), once the somewhat implausible nonparametric results are excluded.

16. We do not report 't-values' for the mean and median slopes in the case of nonparametric estimation, as it is not clear how these should be computed. 